Journal of Bangladesh Academy of Sciences, Vol. 36, No. 2, 251-255, 2012

- Short communication

\title{
INFLUENCE OF TERMINAL BUD PINCHING ON GROWTH AND YIELD OF CHRYSANTHEMUM, CHRYSANTHEMUM INDICUM L.
}

\author{
S.U. HABIBA, M.S. ISLAM AND A.F.M. JAMAL UDDIN* \\ Department of Horticulture, Sher-e-Bangla Agricultural University, Dhaka-1207, \\ Bangladesh
}

\section{ABSTRACT}

An experiment on pinching (viz. $\mathrm{P}_{0}$; without pinching and $\mathrm{P}_{1}$; with pinching) with 3 replications showed the tallest $(37.7 \mathrm{~cm})$ and the shortest plant $(33.4 \mathrm{~cm})$ without pinching and with pinching, respectively. Maximum number of leaves (30.1) and flowers (58.7) per plant were recorded following pinching $\left(\mathrm{P}_{1}\right)$; and minimum number of leaves (26.8) and flowers (37.9) per plant were from without pinching $\left(\mathrm{P}_{0}\right)$.

Key words: Pinching, Chrysanthemum indicum, Flower, Terminal bud, Growth, Yield

Chrysanthemum (Chrysanthemum indicum L.) is a popular flower plant, belongs to Asteraceae. Chrysanthemum, commonly known as the Mum flower, is one of the most popular decorative flowers in the world. In recent years, demand for pot plants for house decoration and for use in amenity horticulture, in many countries in the world has steadily been increased for their outstanding aesthetic beauty, long lasting quality, and their good prospect of marketing as cut flowers and potted plants (Erler and Siegmund 1986). It is also very popular in floral bouquets and flower arrangements. A large number of chrysanthemum cultivars are the result of selection by growers and breeders in many centuries. The climatic condition of Bangladesh is well-adapted for cultivation of chrysanthemum but it's commercial production in Bangladesh is very low. It grows well in sandy loam soil with high light intensity.

Pinching is removing the terminal growing portion of stem mainly for inducing branch and also to reduce the plant height. Pinching makes chrysanthemums compact, bushy plants, with more blooms. The plant height, stem diameter and number of inflorescences increase in the number of pruning's (Brum et al. 2007). In Bangladesh, only limited studies have been done on pinching for growth and yield of chrysanthemums. The present research work was undertaken to study the effects of pinching on growth and yield of chrysanthemum.

The experiment was conducted at Horticulture Farm, Sher-e-Bangla Agricultural University, Dhaka, Bangladesh during October, 2008 to March, 2009 in CRD with three

\footnotetext{
*Corresponding author:<jamal4@yahoo.com>.
} 
replications. Suckers of chrysanthemum were collected from a nursery of Dhaka. Sandy loam soil and cow-dung (1.5 kg/pot, 12 inch size pot) were mixed and pots were filled a few days before transplanting. The experiment considered with and without pinching $\left(\mathrm{P}_{0}\right.$; $\mathrm{P}_{1}$, pinching of plant meant removal of $2.0-2.5 \mathrm{~cm}$ and without pinching meant non removal of the tip of apical bud).

Suckers were planted at $7 \mathrm{~cm}$ depth on 15 October, 2008 with single plant in each pot. During the early growing stage, powdery mildew and leaf spots were controlled by spraying dithane M-45. Fungicide was sprayed twice at 15 days interval. Aphid was controlled by spraying malathion@1.5 ml/1 twice at seven days interval. Data were collected on plant height, number of leaves, branches and yield of flower per plant from each pot within the period mentioned above. Data were statistically analyzed using MSTAT program. Mean for all the treatments was calculated and the analysis of variance for each of the characters was performed by $\mathrm{F}$ test. Difference between treatments was evaluated by DMRT at the 5\% level of significance (Gomez and Gomez 1984).

The experiment was carried out to find out the influence of pinching on growth and yield of chrysanthemum.

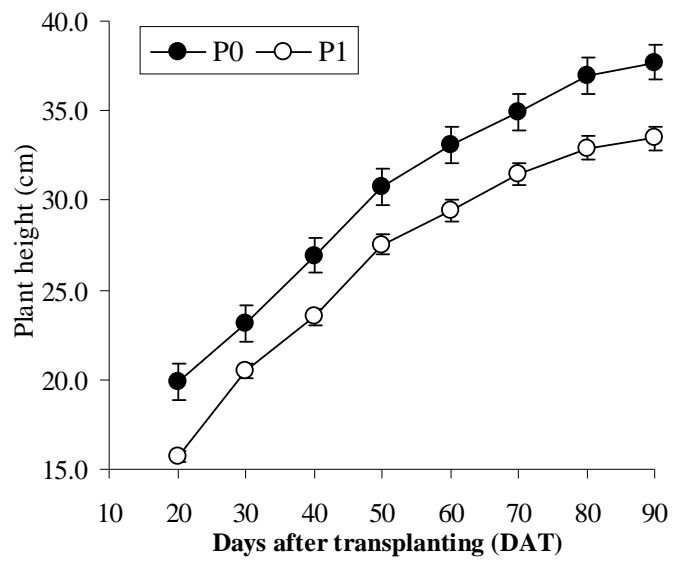

Fig. 1. Effect of terminal bud pinching on plant height of chrysanthemum; without $\left(\mathrm{P}_{0}\right)$ and with $\left(\mathrm{P}_{1}\right)$ pinching

Significant variation was recorded at 20, 30, 40, 50, 60, 70, 80 and 90 DAT for plant height due to the terminal bud pinching in chrysanthemum only once. Gradual increasing trend of plant height was observed with DAT (Fig. 1). Tallest plant was recorded from $\mathrm{P}_{0}$ and the shortest was found from $\mathrm{P}_{1}$ with 90 DAT. Similar result was also reported by Rakesh et al. (2005).

Number of leaves per plant showed significant differences with pinching at 20,30, 50, 60, 70, 80 and 90 DAT but non-significant at 40 DAT. Gradual increasing trend of 
number of leaves per plant was observed with days after transplanting. At 90 DAT the maximum number of leaves per plant was recorded for $\mathrm{P}_{1}$, while the minimum number of leaves was obtained from $\mathrm{P}_{0}$ (Fig. 2).

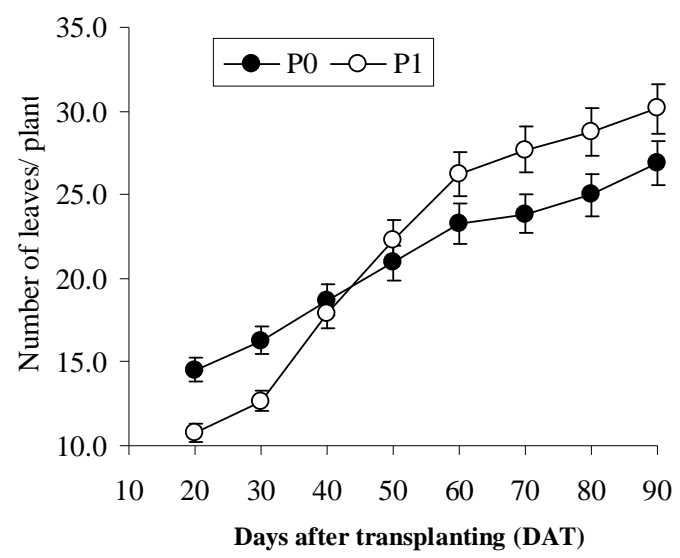

Fig. 2. Effect of terminal bud pinching on number of leaves/plant of chrysanthemum.

Pinching in chrysanthemum showed significant variation for number of branches per plant at 20,30, 40,50,60, 70, 80 and 90 DAT. At 90 DAT the maximum number of branches per plant (4.4) was obtained from $\mathrm{P}_{1}$, whereas the minimum branches per plant (3.4) in $\mathrm{P}_{0}$ (Fig. 3). Similar opinion was also put forward earlier by Beniwal et al. (2003) in case of terminal bud pinching.

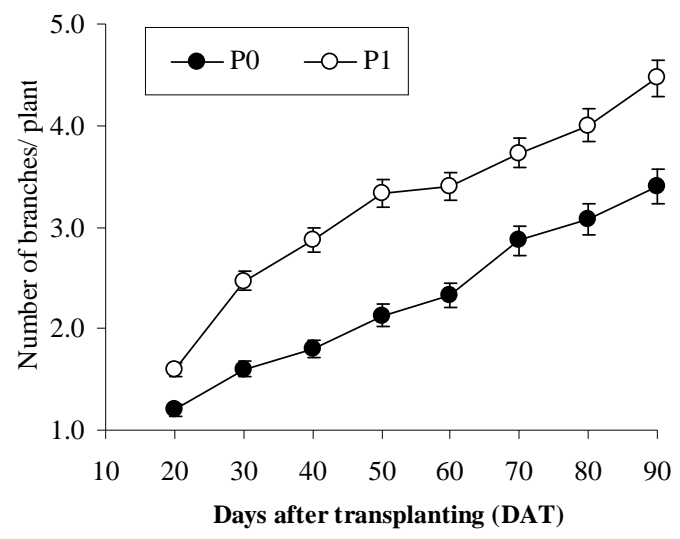

Fig. 3. Effect of terminal bud pinching on number of branches/plant of chrysanthemum.

Number of flowers per plant showed significant differences due to pinching in chrysanthemum at 60, 70, 80, 90, 100, 110, 120 and 130 DAT. Gradual increasing trend of number of flowers per plant was observed with days after transplanting. At 130 DAT the maximum number of flowers per plant (58.7) was obtained from $\mathrm{P}_{1}$ and the minimum 
flowers per plant (37.9) was observed from $\mathrm{P}_{0}$ (Fig. 4). The present result conforms to that of Rakesh et al. (2003, 2004).

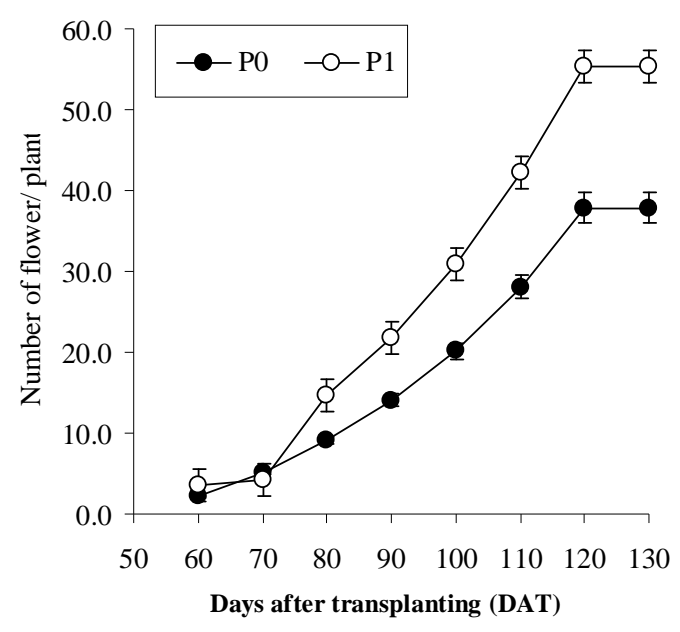

Fig. 4. Effect of terminal bud pinching on number of flower/plant of chrysanthemum.

In the process of pinching when the terminal bud was removed from the plants that attained a stress and plant required times to overcome this condition and the growth was hampered. Natural auxin concentration in the tip of plant causes to grow tall. Pinching temporarily reduces auxin which takes away the apical dominance. This enables the side buds to start growing. On the other hand, in case of without pinching plant exhibits it normal vegetative growth. For that the pinched plant cannot accomplish vegetative growth and the ultimate results were the shortest plant compared to without pinching of terminal bud $\left(\mathrm{P}_{0}\right)$. Without pinching terminal bud helps to attained optimum vegetative growth without disruption of normal plant growth of chrysanthemum. Pinching leads to development of new branches in addition of increasing number of leaves as well as the increased number of flower buds and finally maximum number of flowers in chrysanthemum.

\section{REFERENCES}

Beniwal, B.S., V.P. Ahlawat and K. Rakesh. 2003. Studies on the effect of spacing and pinching on growth and flower production of chrysanthemum cv. Flirt. Haryana Journal of Horticultural Sciences 32: 228-229.

Brum, B., V.J. Santos, M.A. Rodrigues, R.A. Belle and S.J. Lopes. 2007. Growth, duration of the growing stages and inflorescence production of chrysanthemum under different prunings and size of pot. Ciencia Rural 37: 682-689.

Erler, R. and I. Siegmund.1986. Yearbook of the International horticultural statistics. USA. p. 44. 
Gomez, K.H. and A.A. Gomez. 1984. Statistical Procedures for Agricultural Research. Second Edn. Wiley- Inter Science publication, JohnWiley and Sons, New York. pp. 680.

Rakesh, K., R.S. Singhrot and B.S. Beniwal. 2003. Effect of $\mathrm{GA}_{3}$ and pinching on the growth and yield of chrysanthemum. Haryana Journal of Horticultural Sciences 32: 61-63.

Rakesh, K., R.S. Singhrot, B.S. Beniwal and S.K. Moond. 2004. Effect of $\mathrm{GA}_{3}$ and pinching on quality and yield of flowers in chrysanthemum. Haryana Journal of Horticultural Sciences 33: $224-226$.

Rakesh.K., R.S. Singhrot, R.P. Singh and J.R. Sharma. 2005. Flowering and yield response of Chrysanthemum to $\mathrm{GA}_{3}$ and pinching treatments. Haryana Journal of Horticultural Sciences 34: 93-94.

(Received revised manuscript on 16 April, 2012) 